Published in final edited form as:

Mov Disord. 2012 February ; 27(2): 293-297. doi:10.1002/mds.24012.

\title{
Environmental tobacco smoke and Parkinson disease
}

\author{
Susan Searles Nielsen ${ }^{1}$, Lisa G. Gallagher ${ }^{1}$, Jessica I. Lundin ${ }^{1}$, W.T. Longstreth $\mathrm{Jr}^{2,3}$, Terri \\ Smith-Weller ${ }^{1}$, Gary M. Franklin ${ }^{1}$, Phillip D. Swanson ${ }^{2}$, and Harvey Checkoway ${ }^{1,3}$ \\ ${ }^{1}$ University of Washington, Department of Environmental and Occupational Health Sciences, \\ Seattle, Washington \\ 2University of Washington, Department of Neurology, Seattle, Washington \\ ${ }^{3}$ University of Washington, Department of Epidemiology, Seattle, Washington
}

\begin{abstract}
Background-Parkinson disease is inversely associated with cigarette smoking, but its relation with passive smoking or environmental tobacco smoke exposure is rarely examined.

Methods-Within a case-control study we assessed the association between Parkinson disease and living or working with active smokers. Cases were newly diagnosed with idiopathic Parkinson disease (N=154) from western Washington State in 2002-2008. Age- and sex-matched controls $(\mathrm{N}=173)$ were neurologically normal and unrelated to cases.

Results-Compared with never active or passive tobacco smokers, we observed similarly reduced Parkinson disease risks for ever passive smokers only (odds ratio $=0.34,95 \%$ confidence interval $0.16-0.73$ ) as for ever active smokers $(0.35,0.17-0.73)$. Among persons whose only tobacco smoke exposure was passive smoking at home, risk was inversely associated with years exposed.
\end{abstract}

Conclusion-These observations parallel those well-established for active smoking. However, it remains unresolved whether a true protective effect of tobacco smoke, generally detrimental to health, underlies these associations.

\section{MeSH Key Words}

Environmental Tobacco Smoke Pollution; Idiopathic Parkinson Disease; Passive Smoking; Smoking

Corresponding Author: Susan Searles Nielsen, University of Washington, Department of Environmental and Occupational Health Sciences, Box 357234, Seattle, WA 98195-7234, Phone: (206) 685-2487, Fax: (206) 685-3990, ssn@u.washington.edu.

Author Roles: Searles Nielsen: Statistical analysis design and execution; writing of the first manuscript draft; Gallagher: Review and critique of statistical analysis and manuscript; Lundin: Research project execution; review and critique of manuscript; Longstreth: Research project execution; review and critique of manuscript; Smith-Weller: Research project execution; review and critique of manuscript; Franklin: Research project execution; review and critique of manuscript; Swanson: Research project execution; review and critique of manuscript; Checkoway: Research project conception, organization and execution; statistical analysis design and critique; and manuscript review and critique.

Full Financial Disclosures: Searles Nielsen: University of Washington (employment), Fred Hutchinson Cancer Research Center (employment), University of Utah (honorarium for working group on use of residual dried blood spots from newborn screening); Gallagher: University of Washington (employment); Lundin: University of Washington (employment); Longstreth: University of Washington (employment); Harborview Medical Center (employment); National Institutes of Health (NIH, grants and contracts); Smith-Weller: University of Washington (employment); Gary M. Franklin: University of Washington (employment); Swanson: University of Washington (employment); Checkoway: University of Washington (employment); NIH (grants); and Alcoa Co., E.I. Dupont de Nemours Co. and the Electric Power Research Institute (occupational and environmental health advisory boards).

Financial Disclosure/Conflict of Interest: None 


\section{Introduction}

Epidemiologic studies consistently observe markedly reduced risks for Parkinson disease (PD) in relation to ever having smoked cigarettes. ${ }^{1-5}$ Most studies indicate that additional reduction is conferred by increased smoking, assessed by packs per day, years smoked, pack-years, or an apparent inability to quit smoking. This association may reflect a neuroprotective effect of nicotine or other components of tobacco smoke. ${ }^{6,7}$ Alternatively, persons predisposed to PD may have different responses to nicotine, such as altered nicotine metabolism or preclinical differences in dopaminergic neurons, which are central to both PD pathogenesis and nicotine addiction. Although genetics also play a role for both $\mathrm{PD}^{8}$ and nicotine dependence, ${ }^{9}$ twin studies ${ }^{10-12}$ indicate that genes per se are unlikely to underlie the PD-smoking relation.

Understanding whether smoking protects against PD or whether preclinical PD results in either reduced smoking or cessation has important implications for prevention and treatment. One possible approach is to examine whether PD is associated with "passive smoking" or exposure to environmental tobacco smoke (ETS), the smoke and contaminants either released from burning tobacco products or exhaled during active smoking. ETS contains the same constituents as actively inhaled tobacco smoke, ${ }^{13}$ but exposure may be less influenced by one's predilection to smoke.

Despite extensive prior research on PD and active smoking, passive smoking has received little attention, and results have been mixed. Two studies suggested an inverse, doseresponse association with ETS, but risk estimates were imprecise. ${ }^{14,15}$ Also the association was not clearly accentuated among those who had never been active smokers, the group for which ETS exposure would be expected to show the strongest association. In contrast, no inverse association was found in a recent study. ${ }^{16}$ These studies either focused on one source of ETS (parents), ${ }^{15}$ or treated exposure to ETS at home and work as inherently dissimilar, with those exposed at one location being included in the reference group for the other. ${ }^{14,16}$ Within a case-control study with newly diagnosed cases and the expected PDactive smoking associations, ${ }^{17}$ we examined the relation between PD and ETS at home and work.

\section{Methods}

Idiopathic PD cases ( $\mathrm{N}=490)$, diagnosed or prescribed anti-parkinsonian medications during 1992-2008, were identified at Group Health Cooperative $(\mathrm{N}=387)$ or the University of Washington Neurology Clinic ( $\mathrm{N}=103)$ in western Washington State, as described previously. ${ }^{17}$ Briefly, all cases had two or more cardinal signs of PD (bradykinesia, resting tremor, cogwheel rigidity, postural reflex impairment). Diagnoses not made by neurologists were verified by chart reviews by three neurologist co-investigators (GMF, WTL, PDS). All cases were interviewed within 4 years of diagnosis, most (92\%) within 1 year. Controls $(\mathrm{N}=644)$, unrelated to cases, were neurologically normal Group Health enrollees, frequency matched to cases on age, sex, race/ethnicity, clinic and length of enrollment. ${ }^{17}$ We assessed active tobacco smoking histories through a structured, in-person questionnaire. In later interview years (2004-2008), we administered an expanded questionnaire inquiring whether participants (154 cases, 173 controls) had "ever lived with someone who smoked daily" and had "ever worked with people who smoked daily." Parallel questions elicited how many smokers they lived and worked with, and for how many years. Response to all ETS questions was complete. All study procedures were approved by University of Washington and Group Health Cooperative Institutional Review Boards, and all subjects provided written informed consent. 
Because ETS may be chemically similar regardless of location, our primary exposure indicator was ever living or working with a daily smoker, that is, any ETS exposure at home or work. However, since the concentration, duration and co-exposures might differ by location, we secondarily considered residential and workplace ETS separately. Associations of PD and ETS among those who had never been active smokers were of particular a priori interest, because active smoking might overwhelm ETS exposure. We defined active smokers as those who ever smoked $>100$ cigarettes or ever regularly smoked cigars or pipe.

We estimated ${ }^{18}$ odds ratios (ORs) and $95 \%$ confidence intervals (CIs) using unconditional logistic regression, adjusting a priori for race/ethnicity (non-Hispanic Caucasian vs. other), age (continuous) and sex, and other factors only if risk estimates materially changed. We used a multiplicative interaction term between ETS and active smoking to assess whether the PD-ETS association differed between those who had and had not ever been active smokers.

\section{Results}

Most subjects with ETS data were non-Hispanic white (91\% cases, $93 \%$ controls), male (66\% cases, 69\% controls), and born before 1950 (84\% cases, 92\% controls). All cases were diagnosed in 2002-2008, most (71\%) at age 60 years or older (median 66 years). Age at reference was $\geq 60$ years for $77 \%$ of controls (median 70 years). Most Group Health Cooperative participants (69\% cases, all controls) had been enrolled for $\geq 10$ years ( $90 \%$ cases, $88 \%$ controls). Fifty-one percent of cases and $59 \%$ of controls had ever been active tobacco smokers. College degrees (53\% cases, $49 \%$ controls), daily caffeinated coffee consumption (67\% cases, 69\% controls) and any regular alcohol consumption (58\% cases, $65 \%$ controls) were common. Relatively few participants had a first-degree relative with PD ( 9 cases, 5 controls), had never been married ( 9 cases, 5 controls), or had never worked outside the home (1 case, 1 control).

Compared with those who had never been active or passive smokers, we observed a similarly reduced PD risk for only ever having been exposed to ETS (OR=0.34, 95\% CI $0.16-0.73$, Table 1$)$ as for ever active smoking $(\mathrm{OR}=0.35,95 \%$ CI $0.17-0.73$, Table 2$)$. When we compared those who both actively and passively smoked to those who only actively smoked, no inverse association between PD and passive smoking was noted $(\mathrm{OR}=1.57,95 \% \mathrm{CI} 0.62-3.96$, Table 1 footnote), in contrast (interaction $\mathrm{p}$-value $=0.01)$ to the strong inverse PD-passive smoking association noted above among never active smokers. These associations were similar among men and women (Table 1), and whether ETS exposure occurred at home or work (Table 2). Results were unaltered when we either excluded cases ascertained outside of Group Health Cooperative, or adjusted for education, birth year and typical consumption of alcohol and caffeinated coffee (both passive and active smoking ORs $0.33-0.36$, both interaction p-values $0.01-0.02$, data not shown in tables).

When we considered the number of active smokers at home or at work, and the number of years ETS-exposed at each location, a dose-related reduced PD risk was not evident, with one exception that was based on only 18 cases and 25 controls. Among individuals only exposed to tobacco smoke through passive smoking at home, PD risk was inversely related to the number of years living with a daily smoker (OR=0.86, 95\% CI $0.75-0.99$ per year). Ten $(56 \%)$ cases and $5(20 \%)$ controls (Fisher's exact $\mathrm{p}=0.02)$ lived with a daily smoker for $<18$ years, the mode for cases and controls. 


\section{Discussion}

Building on a case-control study of PD with the well-established inverse association with active tobacco smoking, we observed a strikingly similar association between PD and passive smoking. As might be anticipated, the inverse association between PD and ever having lived or worked with a daily smoker was confined to individuals who had never been active smokers themselves, i.e., those presumably otherwise without tobacco smoke exposure. Moreover, we observed the inverse PD-ETS association in both men and women, and with ETS exposure at both home and work. The strength and consistency of these results are noteworthy but should be interpreted cautiously. Our sample size was modest, and the only dose-response association was for the number of years living with daily smokers among individuals with no other active or passive smoking. The lack of other doseresponse associations may suggest this was a chance finding. Alternatively, the number of years living with a smoker may be the only indicator that sufficiently approximated the number of cigarettes smoked indoors (the foremost predictor of indoor nicotine concentrations ${ }^{13}$ ) or whether parents were nicotine dependent (smoked for all 18 years that participants typically may have lived with them). In an analysis focused on parental smoking in large American cohorts of health professionals, an inverse trend was found between PD and the number of parents who smoked while living with them $(\mathrm{RR}=0.87$ for one parent and $\mathrm{RR}=0.73$ for both parents, relative to neither parent). ${ }^{15}$

Our results also share some similarity with those from a case-control study in Australia, ${ }^{14}$ which observed ORs of 0.58 and 0.65 , respectively, for ever having lived with a smoker and ever having worked in a smoky workplace. Among never smokers, ORs were 0.52 and 0.80 , respectively. A subsequent case-control study in Japan likewise considered ETS at home and work as separate exposures, but failed to confirm these findings (ORs of 0.99 and 1.09), despite focusing on those who were never active smokers. ${ }^{16}$ Our analysis suggests the need to avoid diluting a reference group with individuals regularly exposed to ETS in any location, including through their own smoking.

Our passive smoking results parallel the well-established associations ${ }^{1-5}$ for active smoking: Any potentially protective effect is apparent with ever exposure, with only modest additional protection with increasing exposure. Further, risk estimates for active and passive smoking were strikingly similar in magnitude. Many constituents of actively inhaled tobacco smoke, including nicotine, are more concentrated in ETS, ${ }^{13}$ and living or working with active smokers increases urinary nicotine, although levels are modest relative to active smokers. ${ }^{19}$ Thus, insofar as active smoking reduces PD risk, ETS might also possibly confer protection. However, as with active smoking, any association between PD and passive smoking may simply reflect risk aversion or unpleasant response to tobacco smoke, so it remains unknown whether active or passive smoking, which are generally detrimental to health, provide any true protection against PD.

Larger samples with more detailed data on ETS exposure should be pursued to confirm and extend our results. Further investigation of the relation between PD and passive smoking has the potential to shed new light on PD etiology and prevention.

\section{Acknowledgments}

We thank Ms. Karen M. Powers for her work as study coordinator and for suggesting the addition of the ETS questions to the revised questionnaire.

Funding: NIH, National Institute of Environmental Health Science R01ES10750 and P42ES04696. 


\section{References}

1. Chen H, Huang X, Guo X, et al. Smoking duration, intensity, and risk of Parkinson disease. Neurology. 2010; 74:878-884. [PubMed: 20220126]

2. De Palma G, Dick FD, Calzetti S, et al. A case-control study of Parkinson's disease and tobacco use: gene-tobacco interactions. Mov Disord. 2010; 25:912-919. [PubMed: 20461808]

3. Hernan MA, Takkouche B, Caamano-Isorna F, Gestal-Otero JJ. A meta-analysis of coffee drinking, cigarette smoking, and the risk of Parkinson's disease. Ann Neurol. 2002; 52:276-284. [PubMed: 12205639]

4. Ritz B, Ascherio A, Checkoway H, et al. Pooled analysis of tobacco use and risk of Parkinson disease. Arch Neurol. 2007; 64:990-997. [PubMed: 17620489]

5. Thacker EL, O'Reilly EJ, Weisskopf MG, et al. Temporal relationship between cigarette smoking and risk of Parkinson disease. Neurology. 2007; 68:764-768. [PubMed: 17339584]

6. Quik M, Huang LZ, Parameswaran N, Bordia T, Campos C, Perez XA. Multiple roles for nicotine in Parkinson's disease. Biochem Pharmacol. 2009; 78:677-685. [PubMed: 19433069]

7. Castagnoli K, Murugesan T. Tobacco leaf, smoke and smoking, MAO inhibitors, Parkinson's disease and neuroprotection; are there links? Neurotoxicology. 2004; 25:279-291. [PubMed: 14697903]

8. Gasser T. Update on the genetics of Parkinson's disease. Mov Disord. 2007; 22 Suppl 17:S343S350. [PubMed: 18175395]

9. Bierut LJ. Genetic variation that contributes to nicotine dependence. Pharmacogenomics. 2007; 8:881-883. [PubMed: 17716221]

10. Tanner CM, Goldman SM, Aston DA, et al. Smoking and Parkinson's disease in twins. Neurology. 2002; 58:581-588. [PubMed: 11865136]

11. Wirdefeldt K, Gatz M, Pawitan Y, Pedersen NL. Risk and protective factors for Parkinson's disease: a study in Swedish twins. Ann Neurol. 2005; 57:27-33. [PubMed: 15521056]

12. Bharucha NE, Stokes L, Schoenberg BS, et al. A case-control study of twin pairs discordant for Parkinson's disease: a search for environmental risk factors. Neurology. 1986; 36:284-288. [PubMed: 3945402]

13. Jaakkola MS, Jaakkola JJ. Assessment of exposure to environmental tobacco smoke. Eur Respir J. 1997; 10:2384-2397. [PubMed: 9387970]

14. Mellick GD, Gartner CE, Silburn PA, Battistutta D. Passive smoking and Parkinson disease. Neurology. 2006; 67:179-180. [PubMed: 16832110]

15. O'Reilly EJ, Chen H, Gardener H, Gao X, Schwarzschild MA, Ascherio A. Smoking and Parkinson's disease: using parental smoking as a proxy to explore causality. Am J Epidemiol. 2009; 169:678-682. [PubMed: 19131566]

16. Tanaka K, Miyake Y, Fukushima W, et al. Active and passive smoking and risk of Parkinson's disease. Acta Neurol Scand. 2010; 122:377-382. [PubMed: 20175761]

17. Checkoway H, Powers K, Smith-Weller T, Franklin GM, Longstreth WTJ, Swanson PD. Parkinson's disease risks associated with cigarette smoking, alcohol consumption, and caffeine intake. Am J Epidemiol. 2002; 155:732-738. [PubMed: 11943691]

18. StataCorp. Stata statistics/data analysis special edition, version 11.1. College Station, Texas: StataCorp; 2009.

19. Heinrich J, Hölscher B, Seiwert M, Carty CL, Merkel G, Schulz C. Nicotine and cotinine in adults' urine: The German Environmental Survey 1998. J Expo Anal Environ Epidemiol. 2005; 15:74-80. [PubMed: 15150534] 


\section{Table 1}

Risk of Parkinson disease and active and passive tobacco smoking, ${ }^{a}$ overall and by sex, western Washington, 2002-2008

\begin{tabular}{|c|c|c|c|}
\hline \multirow[b]{2}{*}{ Smoking $a$} & \multicolumn{3}{|c|}{ All participants } \\
\hline & $\begin{array}{c}\text { Cases } \\
\mathrm{N}=154 \\
\mathrm{n}(\%)\end{array}$ & $\begin{array}{c}\text { Controls } \\
\mathrm{N}=173 \\
\mathrm{n}(\%)\end{array}$ & OR $(95 \% \mathrm{CI})^{b}$ \\
\hline None & $29(19)$ & $13(8)$ & 1.0 (reference) \\
\hline Passive only & $47(31)$ & $58(34)$ & $0.34(0.16-0.73)$ \\
\hline Active only & $8(5)$ & $16(9)$ & $0.24(0.08-0.71)$ \\
\hline \multirow[t]{3}{*}{ Active and passive } & $70(45)$ & $86(50)$ & $0.37(0.18-0.78)^{c}$ \\
\hline & \multicolumn{3}{|c|}{ Men } \\
\hline & $\begin{array}{l}\text { Cases } \\
\mathrm{N}=101 \\
\mathrm{n}(\%)\end{array}$ & $\begin{array}{c}\text { Controls } \\
\mathrm{N}=120 \\
\mathrm{n}(\%)\end{array}$ & OR $(95 \% \mathbf{C I})^{d}$ \\
\hline None & $18(18)$ & $8(7)$ & 1.0 (reference) \\
\hline Passive only & $27(27)$ & $38(32)$ & $0.29(0.11-0.79)$ \\
\hline Active only & $7(7)$ & $14(12)$ & $0.23(0.07-0.81)$ \\
\hline \multirow[t]{3}{*}{ Active and passive } & 49 (49) & $60(50)$ & $0.37(0.15-0.94)$ \\
\hline & \multicolumn{3}{|c|}{ Women } \\
\hline & $\begin{array}{l}\text { Cases } \\
\mathbf{N}=53 \\
\text { n }(\%)\end{array}$ & $\begin{array}{c}\text { Controls } \\
\mathbf{N}=\mathbf{5 3} \\
\mathbf{n}(\%)\end{array}$ & OR $(95 \% \mathbf{C I})^{d}$ \\
\hline None & $11(21)$ & $5(9)$ & 1.0 (reference) \\
\hline Passive only & $20(38)$ & $20(38)$ & $0.42(0.12-1.47)$ \\
\hline Active only & $1(2)$ & $2(4)$ & $0.20(0.01-2.92)$ \\
\hline Active and passive & $21(40)$ & $26(49)$ & $0.35(0.10-1.18)$ \\
\hline
\end{tabular}

${ }^{a}$ Active smoking $=$ ever smoked $>100$ cigarettes or regularly smoked cigar or pipe; passive smoking $=$ ever lived or worked with daily smoker(s)

${ }^{b}$ Odds ratio and $95 \%$ confidence interval, adjusted for race/ethnicity, sex and age

$c_{\text {Relative to "active only" smokers: } 1.57(0.62-3.96)}$

$d_{\text {Odds ratio and }} 95 \%$ confidence interval, adjusted for race/ethnicity and age 
Table 2

Risk of Parkinson disease and active and passive tobacco smoking, ${ }^{a}$ by passive smoking location, western Washington, 2002-2008

\begin{tabular}{|c|c|c|c|}
\hline Smoking $^{a}$ & $\begin{array}{c}\text { Cases } \\
N=154 \\
n(\%)\end{array}$ & $\begin{array}{c}\text { Controls } \\
\mathrm{N}=173 \\
\mathrm{n}(\%)\end{array}$ & OR $(95 \% \mathrm{CI})^{b}$ \\
\hline None & $29(19)$ & $13(8)$ & 1.0 (reference) \\
\hline Passive at work only ${ }^{c}$ & $8(5)$ & $16(9)$ & $0.22(0.07-0.65)$ \\
\hline Passive at home only ${ }^{c}$ & $18(12)$ & $25(14)$ & $0.28(0.11-0.70)$ \\
\hline Passive only, both locations ${ }^{c}$ & $21(14)$ & $17(10)$ & $0.53(0.21-1.35)$ \\
\hline Active $^{d}$ & $78(51)$ & $102(59)$ & $0.35(0.17-0.73)$ \\
\hline
\end{tabular}

${ }^{a}$ Active smoking $=$ ever smoked $>100$ cigarettes or regularly smoked cigar or pipe; passive smoking = ever lived or worked with daily smoker(s)

${ }^{b}$ Odds ratio and $95 \%$ confidence interval, adjusted for race/ethnicity, sex and age

$c_{\text {No active smoking }}$

${ }^{d}$ With or without passive smoking at home and/or work 